\title{
Stents for Idiopathic Intracranial Hypertension: Meta-Analyzed, Hypo-Analyzed, and In Need of a Trial
}

$\mathrm{H}$ ow did the recent article by Satti et $\mathrm{al}^{1}$ pass muster? A review of the status of venous sinus stent placement in $2013^{2}$ included more patients with stents than the so-called meta-analysis review in your October 2015 issue. Seven of the studies cited in the 2013 analysis had only 1 patient each and were not included in the 2015 analysis; stripped of those 7 single patient studies, the 2015 meta-analysis looks much like the 2013 review. Nevertheless, why choose to include in the meta-analysis a study with only 4 patients-or the studies with only $10,12,15$, or 18 patients? The power in both the 2013 review and the current meta-analysis lies in the 52-patient study by Ahmed et $\mathrm{al}^{3}{ }^{3}$ in which CSF opening pressure, an essential criterion for the diagnosis of idiopathic intracranial hypertension (IIH), was not documented in either 11 or 9 patients depending on which meta-analysis one chooses to read. Likewise, the 2 studies with 15 patients each (Fields et $\mathrm{al}^{4}$ and Albuquerque et $\mathrm{al}^{5}$ ) did not record the CSF opening pressure for any of their included patients; and both the 4-patient study (Owler et $\mathrm{al}^{6}$ ) and the 18-patient study (Kumpe et $\mathrm{al}^{7}$ ) did not record CSF opening pressure in 1 and 4 patients, respectively. A study of 10 patients noted to be without recorded CSF opening pressures in the 2013 analysis (Bussière et $\mathrm{al}^{8}$ ) is noted in Table 4 of the 2015 meta-analysis as having an opening pressure range of $25-50 \mathrm{~cm} \mathrm{H}_{2} 0$. What was the source of that post hoc information?

Given that an elevated CSF pressure is an essential diagnostic criterion of $\mathrm{IIH}$, for which all of these patients were treated, it is therefore possible that as many as 56 of the patients included in the meta-analysis did not meet the criteria for diagnosis of the disease and should not be included in any study of IIH. Given that so little regard was shown for adherence to strict diagnostic criteria to establish the presence of IIH, it is no wonder that there is absolutely no mention of poststenting CSF opening pressure in any of the included studies, which is remarkable because failing to do so missed an opportunity to establish causality. The authors are correct in noting that future studies of operative techniques for this disease should include pre- and postintervention CSF studies, of which I

http://dx.doi.org/10.3174/ajnr.A4642 would suggest that at a minimum these require documented CSF pressures in all patients.

Whether or no IIH actually existed, all patients in the metaanalysis studies underwent the stent-placement procedure and were subject to subsequent complications. Subdural hematoma, noted in passing as a major complication in the metaanalysis, is treated more rigorously in the 2013 review, which noted that all cases of recorded subdural hematomas were treated with open surgical decompression. Therefore, the possibility exists that at least some patients who did not meet the criteria for a diagnosis of IIH underwent an unnecessary procedure that caused a life-threatening complication requiring an emergent operation. Also treated in passing are the 8 patients in the meta-analyzed studies who underwent re-stenting for in-stent/peri-stent restenosis-events that are normally noted as complications in most studies of vascular stents but not so in the Satti article where they are neither listed as complications nor listed as "revisions" in Table 4. There is also the possibility that the $2.2 \%$ conversion rate to another treatment technique noted in the meta-analysis may not be accurate. A study from a dedicated multidisciplinary IIH treatment center that is not referenced in the meta-analysis (Goodwin et $\mathrm{al}^{9}$ ) reported that 3 of $18(16.6 \%)$ patients failed venous sinus stent placement and ultimately required a shunt procedure. A conversion to a more invasive procedure as a result of treatment failure should be counted as a complication of the initial procedure.

The only conclusion that can be drawn is that there is a hint of a promise for this procedure in some patients in whom medically refractory IIH is correctly established. Without a controlled trial comparing venous sinus stent placement with either an accepted surgical technique or the best available medical therapy, conclusions cannot be drawn regarding which patients, if any, may benefit from venous sinus stent placement.

\section{REFERENCES}

1. Satti SR, Leishangthem L, Chaudry MI. Meta-analysis of CSF diversion procedures and dural venous sinus stenting in the setting of medically refractory idiopathic intracranial hypertension. AJNR Am J Neuroradiol 2015;36:1899-904 CrossRef Medline

2. Puffer RC, Mustafa W, Lanzino G. Venous sinus stenting for idio- 
pathic intracranial hypertension: a review of the literature. J Neurointerv Surg 2013;5:483-86 CrossRef Medline

3. Ahmed RM, Wilkinson M, Parker GD, et al.Transverse sinus stenting for idiopathic intracranial hypertension: a review of 52 patients and of model predictions. AJNR Am J Neuroradiol 2011;32:1408-14 CrossRef Medline

4. Fields JD, Javedani PP, Falardeau J, et al. Dural venous sinus angioplasty and stenting for the treatment of idiopathic intracranial hypertension. J Neurointerv Surg 2013;5:62-68 CrossRef Medline

5. Albuquerque FC, Dashti SR, Hu YC, et al. Intracranial venous sinus stenting for benign intracranial hypertension: clinical indications, technique, and preliminary results. World Neurosurg 2011;75:648-55 CrossRef Medline

6. Owler BK, Parker G, Halmagyi GM, et al. Pseudotumor cerebri syndrome: venous sinus obstruction and its treatment with stent placement. J Neurosurg 2003;98:1045-55 CrossRef Medline

7. Kumpe DA, Bennett JL, Seinfeld J, et al. Dural sinus stent placement for idiopathic intracranial hypertension. J Neurosurg 2012;116: 538-48 CrossRef Medline

8. Bussière $\mathrm{M}$, Falero R, Nicolle $\mathrm{D}$, et al. Unilateral transverse sinus stenting of patients with idiopathic intracranial hypertension. AJNR Am J Neuroradiol 2010;31:645-50 CrossRef Medline

9. Goodwin CR, Elder BD, Ward A, et al. Risk factors for failed transverse sinus stenting in pseudotumor cerebri patients. Clin Neurol Neurosurg 2014;127:75-78 CrossRef Medline

(1) P. Noonan

Department of Radiology Scott and White Memorial Hospital

Temple, Texas 